\title{
EVALUASI PELAKSANAAN KURIKULUM 2013 DAN KURIKULUM TINGKAT SATUAN PENDIDIKAN (KTSP) PADA PEMBELAJARAN GEOGRAFI DI SMAN KOTA PADANG
}

\author{
Maijem Simponi ${ }^{\mathrm{a}}$, M Iqbal Liayong Pratama ${ }^{\mathrm{b}}$ \\ ${ }^{a}$ Pendidikan Geografi, Sekolah Tinggi Keguruan dan Ilmu Pendidikan Pesisir Selatan,Pesisir Selatan Kode Pos 25666, \\ Indonesia \\ ${ }^{b}$ Jurusan Ilmu dan Teknologi Kebumian, Universitas Negeri Gorontalo, Jl. Jend. Sudirman No.8, Kota Gorontalo,
} Indonesia

\section{INFO ARTIKEL}

\section{Status artikel:}

Diterima: 08-12-2019

Disetujui: 25-02-2020

Tersedia online: 04-03-2020

\section{Kata kunci:}

Evaluasi, Pembelajaran, Kurikulum

Penulis korespondensi:

Maijem Simponi

Pendidikan Geografi, STKIP Pessel

Email: maijemsimponi@gmail.com DOI: 10.34312 /jgej.v1i1.4084

Copyright $(9) 2020$ JGEJ-UNG All Rights Reserved.

\section{ABSTRACT}

Education system has it's own problems. Indonesia's education also involves the challenge of implementing the new curriculum. The schools are not ready yet to implement the new curriculum, the 2013 curriculum. The 2013 curriculum which emphasizes character development, requires teachers to carry out comprehensive learning and a full assessment of each student's development. This study aims to describe and evaluate the implementation of the 2013 Curriculum and SBC in geography learning at High School in Padang city. This research used descriptive qualitative by using purposive sampling. The sample of this paper are teachers and students who teach and learn geographic subject, principals and vice-principals. The Data were collected through observation, interviews and documentation. The results revealed that: (1) Evaluation of the implementation of KTSP; The planning of learning in SBC emphasizes more on the delivery of material whose learning success is measured through cognitive tests. The implementation of KTSP learning is carried out conventionally, depending on the teacher and creative learning. Teachers' creativity in teaching is the main in creating creative learning so that national education goals are achieved. Assessment of KTSP learning uses reference criteria; that is based on what students understand after participating in the learning process, using a test gauge. Learning success can be seen in the acquisition of student learning outcomes. (2)evaluation of the 2013 curriculum, planning is designed based on instructions from the government and must explore all the potentials and abilities of students and all norms of life. The implementation of 2013 curriculum learning, learning is carried out holistically to achieve overall objectives as well, so that all potential students will be explored listed in the four core competencies by using various assessment instruments, Assessment in the 2013 curriculum is carried out based on scientific assessments that assess all potentials possessed by participant. Assessment is not only limited to the test instrument, but also through various instruments.

\begin{abstract}
ABSTRAK
Permasalahan pendidikan masih saja terjadi pada pendidikan di Indonesia. Salah satu masalah dominan yang banyak terjadi saat ini adalah kesiapan sekolah untuk melaksanakan kurikulum baru, yaitu kurikulum 2013. Kurikulum 2013 yang lebih menekankan pada perkembangan karakter lebih menuntut guru untuk melakukan pembelajaran secara menyeluruh dan penilaian yang sepenuhnya dari setiap perkembangan siswa. Penelitian ini bertujuan untuk mendeskripsikan dan mengevaluasi pelaksanaan Kurikulum 2013 dan KTSP pada pembelajaran geografi di SMAN Kota Padang. Metode penelitian yang digunakan adalah deskriptif kualitatif. Informan dalam penelitian ini adalah seluruh warga sekolah yang diambil secara Purposif Sampling, khususnya guru mata pelajaran geografi, siswa, kepala dan wakil kepala sekolah. Data dikumpulkan melalui observasi, wawancara dan dokumentasi dan dianalisis secara deskriptif. Hasil analisis data menemumakan bahwa: (1) Evaluasi pelaksanaan KTSP; Perencanaan pembelajaran pada KTSP lebih menekankan pada pemberian materi yang keberhasilan pembelajaran diukur melalui tes bersifat kognitif. Pelaksanaan pembelajaran KTSP dilaksanakan secara konvensional, tergantung dari guru dan mengkreatifkan pembelajaran. kreativ guru dalam mengajar merupakan modal utama dalam menciptakan pembelajaran kreatif agar tujuan pendidikan nasional tercapai, Penilaian pada pembelajaran KTSP menggunakan acuan kriteria; yaitu berdasarkan apa yang dipahami peserta didik setelah mengikuti proses pembelajaran, dengan menggunakan alat ukur tes. Keberhasilan pembelajaran dilihat dari perolehan hasil belajar siswa. (2) evaluasi kurikulum 2013, perencanaan dirancang atas instruksi dari pemerintah, dan harus menggali semua potensi dan kemampuan peserta didik dan semua norma kehidupan. Pelaksanaan pembelajaran kurikulum 2013, pembelajaran dilaksanakan secara holistic untuk mencapai tujuan yang menyeluruh juga, sehingga
\end{abstract}


semua potensi siswa akan digali yang tercantum dalam empat kompetensi inti dengan menggunakan berbagai instrument penilaian, Penilaian pada pembelajaran kurikulum 2013 dilaksanakan berdasarkan penilaian saintifik yang menilai semua potensi yang dimiliki oleh peserta. Penilaian tidak hanya terbatas pada instrument tes, tetapi juga melalui berbagai instrument.

This open access article is distributed under Creative Commons Attribution-NonCommercial (CC-BY-NC) 4.0 International License

\section{Pendahuluan}

Sekolah merupakan lembaga pendidikan utama yang diharapkan mampu meningkatkan SDM (Sumber Daya Manusia) suatu daerah. Melalui sekolah, masyarakat mempercayakan diri dan keluarga mereka untuk meraih kualitas diri yang dibutuhkan dalam melangsungkan kehidupan. Berbagai upaya telah dilakukan pemerintah dalam meningkatkan proses pendidikan di sekolah. Salah satu bentuk kepedulian pemerintah dalam bidang pendidikan adalah dengan keluarnya Undang-Undang Nomor 20 Tahun 2003 pasal 3.

Dari undang-undang pendidikan di atas, dapat digambarkan bahwa begitu luasnya tujuan pendidikan yang diharapkan dan tujuan tersebut telah mencakup pada indikator kualitas manusia yang terlihat dari segi ilmu pengetahuan dan wawasan, spritual, emosional, dan keterampilan. Selain itu, peningkatan kualitas sekolah juga terlihat dari adanya otonomi daerah yang memberikan kewenangan bagi sekolah untuk memberikan mata pelajaran muatan lokal bagi peserta didik sesuai dengan keadaan dan tuntutan daerah masing-masing.

Lebih lanjut, usaha pemerintah tersebut juga terlihat dari adanya pergantian kurikulum pendidikan di Indonesia yang selalu menyesuaikan pendidikan dengan perkembangan zaman yang dimulai dari kurikulum 1947, kurikulum 1964, kurikulum 1968, kurikulum 1975, kurikulum 1984, kurikulum 1994, suplemen kurikulum 1999, kurikulum berbasis kompetensi 2004, KTSP (Kurikulum Tingkat Satuan Pendidikan) 2006 dan terakhir adalah kurikulum 2013 (Muhammedi, 2016).

Kurikulum merupakan inti dari proses pendidikan. Hasil pendidikan akan secara langsung dipengaruhi oleh kurikulum (Sukmadinata, 2012). Kurikulum menentukan proses, tujuan, hasil suatu sistem pendidikan, dan juga sebagai pedoman dalam pelaksanaan pengajaran pada semua tingakat dan jenis pendidikan (Arifin, 2011). Adanya pergantian kurikulum pendidikan di Indonesia menandakan bahwa demi meraih kualitas pendidikan yang baik, sistem pendidikan di Indonesia selalu diubah mengiringi perkembangan dan tuntutan ilmu pengetahuan dan teknologi dengan harapan pendidikan Indonesia tidak ketinggalan dari pendidikan negara maju lainnya. Namun permasalahan pendidikan masih saja terjadi pada pendidikan di Indonesia. Salah satu masalah dominan yang banyak terjadi saat ini adalah kesiapan sekolah untuk melaksanakan kurikulum baru, yaitu kurikulum 2013.

Kurikulum 2013 menuntut guru untuk melakukan pembelajaran secara menyeluruh mulai dari penanaman karakter, penggunaan pendekatan saintifik, penilaian integratif (Budiani,et al, 2017). Oleh karena itu, pendidik ataupun seorang guru tidak hanya memberikan penilaian terhadap kemampuan berfikir siswa yang tersaji dalam lembaran hasil belajar, tetapi juga menilai perkembangan kepribadian siswa sehingga pekerjaan guru menjadi lebih banyak dibandingkan dengan pelaksanaan pembelajaran berdasarkan kurikulum KTSP.

Implementasi kurikulum sebagai operasionalisasi konsep kurikulum yang masih bersifat potensial (tertulis) menjadi aktual dalam bentuk kegiatan pembelajaran (Majid and Rochman, 2015). Pembelajaran dalam kelas menjadi tempat untuk melaksanakan dan menguji kurikulum (Rusman, 2012). Pelaksanan kurikulum pada sekolah dapat berjalan dengan baik dipastikan dengan penerapan kurikulumnya (Puslitbang Kementerian Pendidikan dan Kebudayaan RI, 2016).

Kurikulum sebagai acuan pelaksanaan pembelajaran di sekolah harus terlebih dahulu dipahami secara menyeluruh dan mendalam oleh pendidik, kurikulum menjadi seperangkat instruksi utama oleh pengajar (Rahmawati and Anggraini, 2017). Pada masa awal penggunaan kurikulum 2013 muncul banyak kritikan karena dianggap menimbulkan masalah salah satunya ialah kesiapan guru (Alawiyah, 2015). Selain itu, masalah lain yang timbul seperti kesiapan guru, isi dan kemasan kurikulum, dan multitafsir dalam penggunaannya (Syarwan, 2014).

Hasil pengamatan penulis ke beberapa sekolah dan wawancara kepada beberapa guru geografi di SMA Negeri Kota Padang yang telah menerapkan kurikulum 2013 diperoleh informasi bahwa pelaksanaan pembelajaran (1) guru banyak disibukkan dengan penilaian-penilaian dalam bentuk selebaran yang isinya menilai setiap apa yang dilakukan siswa selama belajar, (2) cakupan materi menjadi kurang terfokus karena banyaknya efek yang dinilai dan ditagih guru kepada siswa, (3) sarana pembelajaran geografi yang masih bermasalah seperti labor yang belum tersedia untuk pembelajaran geografi, alat dan bahan pembelajaran 
geografi pun masih minim, (4) siswa belum pernah diajak langsung ke lapangan dalam rangka mengenali alam dan lingkungan sosial, (5) guru tidak memberikan silabus kepada siswa, hanya menyampaikan tujuan pembelajaran saat pembelajaran di kelas akan dimulai, (6) materi hanya terfokus pada LKS siswa dan menggunakan sumber ajar yang minim.

Berbeda halnya dengan pelaksanaan pembelajaran pada kurikulum 2013, pembelajaran dengan kurikulum KTSP tidaklah sesulit dan sesibuk dari pembelajaran kurikulum 2013. Namun tetap saja dalam pelaksanaan KTSP juga mengalami permasalahan. Permasalahan KTSP ini terlihat dari kurang kreatifnya guru, bahasan dan penataran tentang kurikulum bagi guru terbatas, kurangnya pengawasan terhadap tindak lanjut yang dilakukan guru, peserta didik kurang memperoleh buku-buku yang menunjang, kebanyakan guru-guru hanya merubah nama, format, atau silabus.

Pelaksanaan pembelajaran pada kurikulum 2013 lebih membuat guru tidak fokus dalam belajar karena guru juga diminta untuk melakukan observasi disamping memberikan materi ajar. Selama pembelajaran, guru juga menglamati dan mengisi lembaran observasi dan menganalisis hasil observasi tersebut sehingga tugas guru menjadi lebih banyak. Hal inilah yang menjadikan guru kurang fokus dalam pembelajaran. Begitu juga dalam perancangan metode dan strategi pembelajaran.

Perancangan metode ataupun strategi pembelajaran pada kurikulum 2013 membutuhkan waktu yang lama karena banyaknya indikator kurikulum 2013 yang hendak dicapai, sehingga belum semua guru yang memahami metode pembelajaran kurikulum 2013. Berbeda dengan KTSP, metode ataupun perencanaan pembelajaran tidaklah sedetail kurikulum 2013 karena tidak adanya tuntutan secara tertulis dari setiap perubahan yang ada pada diri siswa. Berdasarkan permasalahan di atas, maka penelitian ini bertujuan untuk mengevaluasi pelaksanaan kurikulum tingkat satuan pendidikan (KTSP) dan Kurikulum 2013 pada pembelajaran geografi di SMAN Kota Padang.

\section{Metode}

Metode penelitian yang digunakan adalah metode kualitatif. Pengumpulan data menggunakan teknik wawancara dengan metode purposive sampling dalam pemilihan informan. Adapun informan penelitian adalah guru mata pelajaran geografi yang merupakan informan kunci (informan utama) guru, siswa, tata usaha, dan wakil kepala sekolah. Data dikumpulkan melalui observasi, wawancara, dan dokumentasi serta menggunakan data sekunder. Data yang telah diperoleh akan dianalis menggunakan teknik analisis deskriptif kualitatif.

\section{Hasil dan Pembahasan}

\subsection{Evaluasi Kurikulum Tingkat Satuan Pendidikan (KTSP) pada SMAN Padang}

Berdasarkan studi dokumentasi penelitian melalui analisis perengkat pembelajaran dan Rencana Pelaksanaan Pembelajaran yang diperoleh dari informan peneliti (guru mata pelajaran Geografi) mengenai perencanaan pembelajaran KTSP maka diperolehlah data seperti yang tersaji berikut ini.

Tabel 1. Analisis evaluasi pembelajaran geografi pada kurikulum KTSP dan 2013

\begin{tabular}{|c|c|c|}
\hline No & Keterangan & Kurikulum KTSP \\
\hline 1 & $\begin{array}{l}\text { Perencanaan } \\
\text { Pembelajaran }\end{array}$ & $\begin{array}{l}\text { 1. Kurikulum KTSP hanya mendeskripsikan standar dan kompetensi } \\
\text { dasar. Guru secara mendiri menentukan indikator dan materi } \\
\text { pelajaran. } \\
\text { 2. Guru dapat merancang rencana pelaksanaan pembelajaran sesuai } \\
\text { dengan kreativitas sendiri } \\
\text { 3. Perencanaan pembelajaran guru lebih menekankan pada hasil } \\
\text { belajar. } \\
\text { 4. Sistem penilaian dan proses pembelajaran yang dirancang lebih } \\
\text { sederhana dibandingkan dengan kurikulum 2013, karena guru } \\
\text { tidak secara khusus melakukan observasi kelas melalui lembaran } \\
\text { observasi }\end{array}$ \\
\hline 2 & $\begin{array}{l}\text { Pelaksanaan } \\
\text { Proses } \\
\text { Pembelajaran }\end{array}$ & $\begin{array}{l}\text { 1. Berbasis kompetensi sehingga peserta didik berada dalam proses pe } \\
\text { rkembangan yang berkelanjutan dari seluruh aspek kepribadian, seb } \\
\text { agai pemekaran terhadap potensi- } \\
\text { potensi bawaan sesuai dengan kesempatan belajar yang ada dan dib } \\
\text { erikan oleh lingkungan. (bedanya dengan kurikulum 2013, tidak } \\
\text { adanya lembaran observasi/angket penilaian kemampuan siswa dari } \\
\text { segi afektif) } \\
\text { 2. Pelaksanaan pembelajaran lebih sederhana karena guru dan siswa }\end{array}$ \\
\hline
\end{tabular}




\begin{tabular}{|c|c|c|c|}
\hline & & 3. & $\begin{array}{l}\text { bisa lebih fokus dalam pembelajaran dengan satu atau dua pokok } \\
\text { bahasan tanpa adanya indicator yang dinilai lainnya. } \\
\text { Pembelajaran dapat dimodifikasi sedemikian rupa karena } \\
\text { tersedianya lebih waktu untuk mengekperimenkan berbagai } \\
\text { metode/model belajar mengajar. }\end{array}$ \\
\hline 3 & $\begin{array}{l}\text { Penilaian dan } \\
\text { Evaluasi } \\
\text { Pembelajaran }\end{array}$ & $\begin{array}{l}1 . \\
2 .\end{array}$ & $\begin{array}{l}\text { Capaian kompetensi diukur berdasarkan penilaian } \\
\text { Kriteria penilaian berdasarkan apa yang bisa dilakukan siswa } \\
\text { setelah mengikuti proses belajar mengajar bukan menilai prosesnya } \\
\text { atau posisinya dalam kelompoknya. } \\
\text { Menggunakan sistem penilaian berkelanjutan yang mana semua } \\
\text { indikator diminta, lalu hasilnya akan dianalisis dipergunakan untuk } \\
\text { menentukan kompetensi yang telah dikuasai maupun yang belum } \\
\text { dikuasai oleh peserta didik dan juga untuk memperoleh informasi } \\
\text { dimana letak kesulitan yang dialaminya. } \\
\text { Hasil analisis dari penilaian akan ditindak lanjut yang berupa } \\
\text { perbaikan proses belajar mengajar, pemberian remedial untuk siswa } \\
\text { yang nilainya dibawah kriteria ketuntasan, dan pengayaan bagi } \\
\text { siswa yang memperoleh nilai diatas kriteria ketuntasan. } \\
\text { Penilaian KTSP berorientasi pada hasil belajar (learning outcomes) } \\
\text { dan keberagaman. } \\
\text { Penilaian menekankan pada hasil belajar dan proses dalam upaya } \\
\text { penguasaan atau pencapaian suatu kompetensi. } \\
\text { Kriteria ketuntasan belajar diharap dapat meningkat secara } \\
\text { berkelanjutan untuk memperoleh kriteria ketuntasan ideal } \\
\text { Setiap indikator dalam ketuntasan belajar yang ditetapkan didalam } \\
\text { suatu kompetensi dasar berkisar antara } 0 \text { - } 100 \% \text {. }\end{array}$ \\
\hline
\end{tabular}

\section{Sumber : Hasil Analisis Data Primer}

1) Evaluasi Perencanaan kurikulum tingkat satuan pendidikan (KTSP) pembelajaran geografi di SMAN Kota Padang

KTSP hanya mendeskripsikan kompetensi dasar (KD) dan standar kompetensi (SK), sehingga guru secara mandiri menentukan indikator dan materi pelajaran yang biasanya disesuaikan dengan kondisi daerahnya dan minat siswa. Sekolah juga diberikan wewenang seutuhnya untuk mengembangkan kurikulum. Oleh karenanya, berhasil atau tidaknya pelaksanaan kurikulum disekolah tergantung kepada kepala sekolah dan guru yang mana mereka memegang perenan kunci dalam menentukan dan menggerakkan komponenkomponen yang ada dilingkungan sekolah.

2) Evaluasi Pelaksanaan kurikulum tingkat satuan pendidikan (KTSP) pembelajaran geografi di SMAN Kota Padang

Pelaksanaan KTSP bermula dari pelaksanaan pembelajaran yang berupa bagaimana caranya agar pesanpesan atau isi dari kurikulum (kompetensi dasar dan standar kompetensi) dapat diterima oleh siswa secara optimal dan tepat. Penerapan kurikulum dalam pembelajaran mencakup 3 kegiatan yakni pembukaan, pembentukan kompetensi dan penutup.

3) Evaluasi Penilaian kurikulum tingkat satuan pendidikan (KTSP) pembelajaran geografi di SMAN Kota Padang

Penilaian pada KTSP memang jauh berbeda dengan kurikulum 2013, karena letak perbedaan utama KTSP dengan kurikulum 2013 memang terletak pada proses dan penilaian/evaluasi hasil belajar. Penilaian/evaluasi pada KTSP dibedakan menjadi 2 hal, yakni penilaian yang dilaksanakan oleh pihak sekolah (pengelola sekolah dan guru) yang disebut dengan evaluasi diri dan penilaian dari luar (badan akreditasi sekolah/badan independen).

a. Evaluasi pelaksanaan kurikulum 2013 pembelajaran geografi di SMAN Kota Padang 
Berdasarkan studi dokumentasi penelitian melalui analisis perengkat pembelajaran dan Rencana Pelaksanaan Pembelajaran yang diperoleh dari informan peneliti (guru mata pelajaran Geografi) mengenai kurikulum 2013 maka diperoleh data seperti yang tersaji berikut ini.

Tabel 2. Analisis evaluasi pembelajaran geografi pada kurikulum KTSP dan 2013

\begin{tabular}{|c|c|c|}
\hline No & Keterangan & Kurikulum 2013 \\
\hline \multirow[t]{5}{*}{1} & Perencanaan & 1. Perlunya mendiskripsikan kompetensi dasar dan kompetensi inti. \\
\hline & $\begin{array}{l}\text { Pembelajara } \\
\mathrm{n}\end{array}$ & $\begin{array}{l}\text { 2. Perencangan rencana pembelajaran didasarkan pada masing-masing } \\
\text { kompetensi inti dengan menintegrasikan masing-masing kompetensi inti } \\
\text { ke dalam pembelajaran. }\end{array}$ \\
\hline & & $\begin{array}{l}\text { 3. Memerlukan kreativitas yang tinggi dalam menyampaikan pembelajaran } \\
\text { agar semua kompetensi inti dapat tersampaikan. }\end{array}$ \\
\hline & & $\begin{array}{l}\text { 4. Perencanaan sistem penilaian yang lebih komplek dan detail untuk tiap- } \\
\text { tiap siswa. }\end{array}$ \\
\hline & & 5. Adanya lembaran observasi penilaian harian untuk masing-masing siswa \\
\hline \multirow[t]{6}{*}{2} & & Pembelajaran dilaksanakan secara saintifik yang tidak hanya melihat \\
\hline & Proses & nomum nrocs noloioron \\
\hline & Pembelajara & xan pada keterampilan proses yang \\
\hline & & dilaksanakan secara inspiratif, menyenangkan, interaktif, menantang, \\
\hline & & $\begin{array}{l}\text { memotivasi peserta didik. Sehingga memerlukan lembaran observasi } \\
\text { dan angket penilaian. }\end{array}$ \\
\hline & & $\begin{array}{l}\text { 2. Penggunaan metode disesuaikan pada karakteristik siswa dan mata } \\
\text { pelajaran dengan proses elaborasi, konfirmasi dan eksplorasi melalui } \\
\text { aktivitas mengamati, menalar, menanya, mencoba, menyaji dan } \\
\text { menciptakan. }\end{array}$ \\
\hline
\end{tabular}

3. Pada kegiatan inti, hal yang dinilai adalah sebagai berikut :
a. Mengamati,
b. Menanya
c. Mencoba
d. Mengasosiasi
e. Mengomunikasikan

3 Penilaian Rumusan standar kompetensi lulusan (Peraturan Menteri Pendidikan dan dan Evaluasi Kebudayaan Nomor 54 tahun 2013) untuk tingkat SMA adalah sebagai Pembelajara berikut.

$\mathrm{n}$

Sikap : Memiliki sikap dan perilaku yang mencerminkan orang beriman, berilmu, percaya diri, berakhlak mulia, bertangggung jawab dalam berinteraksi dengan lingkungan alam dan sosial sebagai cerminan bangsa dalam pergaulan.

Pengetahuan : Memiliki pengetahuan yang konseptual, faktual, metakognitif dan prosedural dalam ilmu pengetahuan dan teknologi, budaya dan seni dengan wawasan kebangsaan, kemanusiaan, peradaban dan kenegaraan terkait penyebab serta dampak kejadian dan fenomena

Keterampilan : Memiliki kemampuan berpikir dan bertindak secara kreatif dan efektif dalam ranah konkrek maupun abstrak sebagai pengembangan yang dipelajari disekolah secara mandiri.

Proses Penilaian : penilaian dilaksanakan berdasarkan penilaian autentik yang dilakukan secara komprehensif. Prosesnya dimulai dari masukan (input), proses, dan keluaran (output) pembelajaran mencakup pengetahuan/kognitif, dan keterampilan dan sikap/afektif. Penilaian pengetahuan melalui tes tertulis, tes lisan, dan penugasan. Penilaian keterampilan melalui tes praktik, penilaian proyek, dan penilaian portofolio. Penilaian sikap dilakukan melalui observasi/pengamatan menggunakan jurnal, penilaian diri,dan penilaian antar teman.

\section{Sumber : Hasil Analisis Data Primer}


1) Evaluasi Perencanaan kurikulum 2013

Tidak jauh berbeda dengan kurikulum KTSP, perencanaan pembelajaran pada kurikulum 2013 sama dengan KTSP, perbedaannya terletak pada penyusunan proses pelaksanaan pembelajaran. Proses penyusunan RPP pada Kurikulum 2013 mendeskripsikan pengorganisasian dan prosedur dalam proses belajar mengajar untuk mencapai kompetensi dasar yang telah ditentukan pada standar isi dan penjabaran dalam silabus.

2) Evaluasi Pelaksanaan kurikulum 2013

Berdasarkan hasil penelitian diketahui bahwa guru telah melakukan pembelajaran sesuai dengan indikator kurikulum 2013, meskipun masih ada beberapa indikator penilaian yang belum terpenuhi. Hal ini terlihat pada kegiatan inti, guru telah melakukan pembelajaran scientific, terlihat dari guru memberikan pembelajaran yang mendidik, guru memberikan penilaian autentik, guru memancing keterlibatan siswa dalam belajar, guru harus menerapkan bahasa yang jelas serta memberikan pembelajaran efektif.

3) Evaluasi Pelaksanaan kurikulum 2013

Pada kurikulum 2013, penilaian dilaksanakan berdasarkan penilaian autentik. Penilaian ini memiliki hubungan yang kuat dengan scientific approach (pendekatan ilmiah) dalam belajar mengajar. Selain itu, penilaian auntentik mampu mendeskripsikan hasil belajar siswa yang meningkat, baik dalam mengamati, bernalar,membangun jaringan, mencoba, dan sebagainya.

\section{Kesimpulan}

Hasil penelitian menunjukkan bahwa (1) Evaluasi pelaksanaan KTSP; Perencanaan pembelajaran pada KTSP lebih menekankan pada pemberian materi yang keberhasilan pembelajaran diukur melalui tes bersifat kognitif. Pelaksanaan pembelajaran KTSP dilaksanakan secara konvensional, tergantung dari guru dan mengkreatifkan pembelajaran. kreativ guru dalam mengajar merupakan modal utama dalam menciptakan pembelajaran kreatif agar tujuan pendidikan nasional tercapai, Penilaian pada pembelajaran KTSP menggunakan acuan kriteria; yaitu berdasarkan apa yang dipahami peserta didik setelah mengikuti proses pembelajaran, dengan menggunakan alat ukur tes. Keberhasilan pembelajaran dilihat dari perolehan hasil belajar siswa. (2) evaluasi kurikulum 2013, perencanaan dirancang atas instruksi dari pemerintah, dan harus menggali semua potensi dan kemampuan peserta didik dan semua norma kehidupan. Pelaksanaan pembelajaran kurikulum 2013, pembelajaran dilaksanakan secara holistic untuk mencapai tujuan yang menyeluruh juga, sehingga semua potensi siswa akan digali yang tercantum dalam empat kompetensi inti dengan menggunakan berbagai instrument penilaian, Penilaian pada pembelajaran kurikulum 2013 dilaksanakan berdasarkan penilaian saintifik yang menilai semua potensi yang dimiliki oleh peserta. Penilaian tidak hanya terbatas pada instrument tes, tetapi juga melalui berbagai instrument.

\section{Referensi}

Ahmad, Syarwan. (2014). Problematika Kurikulum 2013 \& Kepemimpinan Instruksional Kepala Sekolah. Jurnal Pencerahan, 8(2).98-108.

Alawiyah, F. 2014. Kesiapan Guru Dalam Implementasi Kurikulum 2013. Info Singkat, VI(15). 912/L P3DI/Agustus/2014.

Arifin, Zainal. (2011). Konsep \& Model Pengembangan Kurikulum. Bandung: Remaja Rosdakarya. Budiani, S., Sudarmin., Syamwil, R. (2017). Evaluasi Implementasi Kurikulum 2013 di Sekolah Pelaksana Mandiri. Innovative Journal of Curiculum and Educational Technology, 6(1) : 4557.

Majid, A. \& Rusman. (2014). Pendekatan Ilmiah dalam Implementasi Kurikulum 2013. Bandung : PT. Remaja Rosda Karya.

Muhammedi. (2016). Perubahan Kurikulum Di Indonesia : Studi Kritis Tentang Upaya Menemukan Kurikulum Pendidikan Islam Yang Ideal. Jurnal Raudhah, 6(1). 49 - 70

Puslitbang, Kementerian Pendidikan dan Kebudayaan RI. Evaluasi Pendampingan Kurikulum 2013.

Rahmawati, Desi., Anggraini, A.S . (2017). Evaluasi Program Kurikulum Berdasarkan Standar Isi, Standar Proses dan Standar Kompetensi Lulusan di SDN Pisangan Timur 10 Pagi. Jurnal Pendidikan Ekonomi dan Bisnis. 5(1). 35-50

Rusman. (2012). Manajemen Kurikulum. Jakarta : PT. Raja Grafindo Persada. 
Sukmadinata, N.S. (2012). Pengembangan Kurikulum. Bandung: Remaja Rosdakarya. 